\title{
Old or Age Indeterminate Anteroseptal Myocardial Infarction by ECG Finding
}

National Cancer Institute

\section{Source}

National Cancer Institute. Old or Age Indeterminate Anteroseptal Myocardial Infarction

by ECG Finding. NCI Thesaurus. Code C102686.

An electrocardiographic finding of pathologic Q waves in leads V1 through V4, which is suggestive of myocardial infarction of the anteroseptal wall of the left ventricle, without evidence of current or ongoing acute infarction. (CDISC) 